relations to space, and that the order; as a whole, is, as far as yet known, remarkably restricted as regards geological time.

The comparisons instituted in our survey of the frog's anatomy will enable us now to sum up resemblances; first, as regards the orders of its class, and secondly, as regards the class itself.

r. Its own order, Anoura, has been seen to present singular resemblances to the Chelonia amongst reptiles. Such are the bony plates of the back of some forms, the bony covering of the temporal fossa in others, the mode of inspiration in the adult, the armature of the jaws in the young. On the other hand, the peculiar elongated tarsus has reminded us of certain mammals, and the median Eustachian opening of Pipa and Dactylethra has suggested an affinity to crocodiles and birds. It has been plain, however, that these several likenesses, however singular and striking, are not evidences of genetic affinity.

2. The order Urodela may well recall to mind the Lacertilia amongst reptiles, with which animais the Urodela were actually classed by Linneus. Moreover in both groups we find a series of different species, longer and longer in body and shorter and shorter in limb. We have also seen that in both these groups an analogous complication obtains in the muscles of the legs.

3. The order Uphiomorpha, as has been before observed, present a general resemblance to serpents, and a special resemblance to certain short-tailed ones; though it is rather to the Amphisbenian Saurians that they may most advantageously be compared. Here, again, however, we meet with the resemblances which, though striking, do not allow themselves to be interpreted as indices of any special relationship by descent.

4. The order Labyrinthodonta recalls to mind, as has been said earlier, the Crocodilia amongst reptiles, of which they may be deemed as the prophetic precursors, so to speak, though certainly not the direct ancestors.

Thus the class Batrachic, as a whole, presents a very interesting analogy and parallelism with the class Reptilic. It is a parallelism, moreover, which reminds us of that which exists between the various orders of Placental mammals and the great subdivisions of the pouched or Marsupial order of mammals. Wehave carnivorous, insectivorous, arboreal, aquatic, herbivorous, marsupial beasts, as we have carnivorous, insectivorous, arboreal, aquatic and herbivorous placental beasts. The harmonious variations of the placental and marsupial groups thus present us with excellent instances of affinities independently evolved and not due to hereditary influence.

In a similar way it seems probable that the subdivisions (orders) of the class Batrachia, mimic, as it were quite independently, the subdivisions (orders) of the class Reptilia.

The Frogs' class, as a whole, shows as many striking affinities to some or other fisbes. It does so in the possession of gills and of a branchial apparatus during onc time of life at the least; a large parasphenoid in the skull; the often persistently unsegmented terminal part of the notochord; the single ventricular cavity of the heart ; the presence of a bulbus aorta; the development of a nervus lateralis; the communication between the urinary canal and the oviduct, and certain other characters of less importance.

The class Batrachia agrees both with fishes and reptiles in having the blood cold, more than one aortic arch, and (except in crocodiles) in not having the distinct ventricles.

The class agrees with fishes, reptiles, and birds, in having no complete diaphragm, and no corpus callosum* in the brain, and no single aorta arching over the left bronchus.

We have now arrived at the end of those considerations seemingly best suited to enable us to answer the initial question, "What is a Frog?" The requisite definition might, of course, have been given much earlier, but these inquiries have seemed necessary to enable the reader to

* As to this structure see Lesson in "Elementary Anatomy," pp. 367,375 understand the technical terms of such definition-to give them, in his eyes, a real meaning.

The Frog is a tailless, lung-breathing, branchiate vertebrate, with four limbs typically differentiated, undergoing a complete metamorphosis, and provided with teeth along margins of the upper jaw.

The course of our inquiry into the nature and affinities of the Frog has not alone served to answer the question with which this memoir opened. Incidental bearings upon deep biological problems have come before us more than once in its course, nor have all the conclusions which seem to have forced themselves upon us been totally negative.

Thus we have met with several instances of the independent origin of remarkably similar structures, such as a shielded temporal fossa and elongated tarsus, which, together with structures like the tooth of the Labyrinthodon, seem to be characters for the existence of which neither the destructive agencies of nature acting on minute oscillations of structure, nor any sexual phenomena, will account.

Again, in the life-history of the Frog, considered even purely by itself, we find a remarkable example of spontaneous transformations due to innate powers and tendencies.

When, however, this process is considered in the light derived from the curious phenomena of transformation so enigmatically presented to us by the axolotl, we have very strongly brought before us the powerful action of internal tendencies lying dormant and latent till made manifest, through the advent of conditions so obscure that as yet they have evaded the most careful and anxious scrutiny of practised adepts.

It would seem to be a negligence not here to point out, that if new forms of life-new species--arise from time to time through congenital variation, not a few of the facts herein quoted point to the probability that such forms have arisen through the evolutions of implanted potentialities definite in nature, in other words, by "specific genesis."

Again, a general survey of the different kinds of relations which the Frog has brough: before us, is well calculated to impress us with the overwhelming richness and fulness of nature.

Although, from our ignorance, the natural history of many other animals well known to us may appear less replete with interest than that of the common Frog may now be, yet it cannot be doubted but that the progress of science is capable of revealing to us facts as full of instruction and of as profound a significance in the life history of almost any kind of animal whatever.

Ever fresh, ever fertile, natural history offers to our faculties a pursuit practically inexhaustible. We are not, indeed, denied the gratification of successfully exploring and satisfactorily explaining mystery after mystery, but each secret wrested by our efforts brings before us other ever new enigmas, so that though refreshed by success we need never be wearied by monotony. While we need not regard any problem as absolutely hopeless, no dread of coming to the end of our inquiries need ever chill the warmth of our zeal in the scientific cause. Some may consider such reflections justified by the phenomena presented to them by the natural history of the Common Frog.

\section{St. George Mivart}

\section{THE HABITS OF BEES AND WASPS*}

SIR JOHN LUBBOCK, in a paper on the Social Hymenoptera (Bees, Wasps, and Ants), especially with reference to their habits, senses, and power of communication with one another, pointed out with regard to the latter, that the observations on record scarcely justify the conclusions which have been drawn from them.

* Being the substance of a paper by Sir John Lubbock, Rart., F.R.S.; read before the Linnean Society on the 19th March, 187.4. 
Thus Messrs. Kirby and Spence say that ants have a language "not confined merely to giving intelligence of the approach or absence of danger, but co-extensive with all their other occasions for communicating their ideas to each other." The observations, however, on which this statement is based, scarcely seemed to him to be conclusive. The two Hubers, indeed, bad clearly shown that ants and bees could make one another cognizant of their state of feeling, could communicate anger, danger, $\& c .$, but that was very different from the possession of a true language.

In stipport of the opinion that Ants and Bees possess a true language, it is usually stated that if one bee discovers a store of honey, the others are soon aware of the fact. Thus Huber says, "Wasps are also acquainted with the mode of imparting information to their companions. When a single wasp discovers a stronghold of sugar, honey, or other article of food, it returns to its nest, and brings off, in a short time, a hundred other wasps ; but we are yet ignorant, if it be by visible or palpable signs, they are mutually informed of this discovery." *

This, however, does not necessarily imply the possession of any power of describing localities, or anything which could correctly be called a language. If the bees or wasps merely follow their fortunate companions, the matter is simple enough. If, on the contrary, the others are sent, the case would be very different. In order to test this, Sir John proposed to keep honey in a given place for some time, in order to satisfy himself that it would not readily be found by the bees, and then after bringing a bee to the honey, to watch whether it brought others or sent them,- the latter, of course, implying a much higher order of intelligence and power of communication.

In the first place, then, he kept some honey for some days at an open window in his sitting-room, and no bees came to it. He then brought a bee up from his hives in the garden in his hand, choosing one which was in the act of leaving the hive. He found it frightened the bees less to be brought in the hand than in a bottle, probably on account of the darkness. The bee thus brought up was then fed with honey, which it sucked with evident enjoyment for a few minutes, and then flew quietly away. But though it had given no symptom of alarm or annoyance, it did not return, nor did any other bee come to the honey. This experiment he repeated eight times, with a like result. He therefore procured one of Marriott's observatory hives, which he placed in his sitting-room. The bees had free access to the open air, but there was also a small side, or postern door, which could be opened at pleasure, and which led into the room.

This enabled him to feed and mark any particular bees, and he recounted a number of experiments from which it appeared that comparatively few bees found their own way through the postern, while of those which did so, the great majority flew to the window, and scarcely any found the honey for themselves.

Those, on the contrary, which were taken to the honey, passed backwards and forwards between it and the hive, making, on an average, five journeys in the hour. In these cases it is obvious that the bees which had found the honey did not communicate their discovery to the others ; and the postern being small and on one side, few of the bees found it out for themselves. If the honey had been in an open place, no doubt the sight of their companions feasting would have attracted other bees, but in this case the honey was rather out of sight, being behind the hive entrance; and was, moreover, only accessible by the narrow and winding exit through the little postern door.

Sir John had, also, in a similar manner, watched a number of marked wasps with very similar results.

No doubt when one wasp has discovered and is visiting a supply of syrup, others are apt to come too, but he believed that they merely follow one another. $\mathrm{He}$ argued that if they communicated the fact, considerable numbers would at once make their appearance, but he has never found this to be the case. The frequent and regular visits which his wasps paid to the honey put out for them proves that it was very much to their taste. Yet they did not bring their companions with them. For instance, on September I9, when a marked wasp paid more than forty visits to some honey, only one other specimen came to the honey during the whole day. Both these wasps returned on the 2oth, but not one other. The 2 ist was a hot day, and there were many wasps about the house; his honey was regularly visited by the marked wasps, but during the whole day cnly five others came to it.

From these and other observations of the same tendency he concludes that even if bees and wasps have the power of informing one another when they discover a store of good food, at any rate they do not habitually do so, and this seemed to him a strong reason for concluding that they are not in the habit of communicating facts. If they do not, he argues, discuss among themselves the incidents of the day, their adventures in search of food, their success and fortunes in hunting, is it not a fair inference. that they have no power of doing so?

Without in any way regarding the facts now recorded as sufficient or conclusive, he thought they indicated that their communications were confined to the reelings, and that there was no power of transmitting information as to matters of fact.

When once wasps had made themseives thoroughly acquainted with their way, their movements were most regular. They spent three minutes supplying themselves with honey, and then flew straight to the nest, refurning after an interval of about ten minutes, and thus making, like the bees, about five journeys an hour. During September they began in the morning at about 6 o'clock, and later when the mornings began to get cold, and continued to work without intermission till dusk. They made therefore rather more than 50 journeys in the day. In fact they were just as industrious as bees, and kept longer hours, as they began earlier in the morning. He believed that the wasps which seemed to be idling in our rooms had simply lost their way. He gave also a number of observations tending to show the difficulty which bees have in finding their way. For instance, he put a bee into a bell glass 18 inches long with a mouth $6 \frac{1}{2}$ inches in diameter, turning the closed end to the window. The bee buzzed about for an hour, when, as there seemed no chance of her getting out, he released her.

Although, as everyone knows, wasps are easily startler? and very much on the alert, still they are very courageous.

On one occasion one of his marked wasps had smeared herself with honey and could not fly. When this happened to a bee it was only necessary to carry her to the alighting-board, when she was soon cleaned by her comrades. But he did not know where this wasp's nest was, and could not, therefore, pursue a similar course with her. At first he was afraid she was doomed. He thought, however, that he could wash her, fully expecting, indeed, to terrify her so much that she would not return again. He therefore caught her, put her in a bottle half full of water, and shook her up and down well till the honey was washed off. He then transferred her to a dry bottle and put her in the sun. When she was dry he let her out, and she at once flew to her nest. To his surprise, in thirteen minutes she returned as if nothing had happened and continued her visits to the honey all the afternoon. The next morning she was the first to arrive.

He also had made some experiments on the behaviour of bees introduced into strange hives, which seemed to contradict the ordinary statement that strange bees are always recognised and attacked.

Another point as to which very different opinions have 
been established is the use of the antennæ. Some entomologists have regarded them as olfactory organs, some as ears; the weight of authority being perhaps in favour of the latter opinion. In experimenting on his wasps and bees Sir John, to his surprise, could obtain no evidence that they heard at all. He tried them with a shrill pipe, with a whistle, with the violin, with all the sounds of which his voice was capable, doing so, moreover, within a few inches of their head, but they continued to feed without the slightest appearance of consciousness.

Lastly he recounted some observations to show that bees have the power of distinguishing colours. The relations of insects to flowers imply that the former can distinguish colour, but there had been as yet but few direct observations on the point.

\section{THE CAVENDISH LABORATORY}

THIS Laboratory, in which every facility is furnished for the prosecution of physical research, is the munificent gift of William Cavendish, Duke of Devonshire, K.G., Chancellor of the University, who has intimated his intention of presenting it complete to the University.

The building, which is now finished, was erected from the designs of W. M. Fawcett, M.A., of Jesus College, at an expense of about $10,000 l$.

The ground-floor contains a set of rooms for operations requiring great steadiness, such as the measurements of length, time, and mass, and of heat, electricity, and magnetism. A store-room, a workshop, and a battery-room are also provided on the ground-floor.

The first floor contains a spacious lecture-room with a preparation-room, a large apparatus-room, a private room for the professor, and a large working laboratory, fitted with tables standing on beams of their own, so as to be independent of the vibrations of the floor. All the tables in the building are supported in the same way, and there are in every floor small trap-doors, by means of which bodies may be suspended over the tables in the room beneath, and through which electric and other communica ions may be made.

The upper rooms are intended for acoustics, radiant heat, optics, electricity, and the graphic reduction of observations. There is also a dark room for photographic 1 repafations. The air in the electric room will be kept di by a contrivance due to Mr. Latimer Clark, and the electric machine worked in this room may be made to 1 rnish electricity for experiments in the lectureroom.

In the tower will be erected an iron tube, which may be filled with mercury so as to measure the greater pressures to which gases and vapours are subjected in the heatroom on the ground-floor. There is also an arrangement by which the electric potential of the air at the top of the tower may be measured either in the lecture-room or in the electric-room.

The laboratory is open daily from ro A.M. till 6 P.M. under the superintendence of the Professor of Experimental Physics, for the use of any member of the University who may desire to acquire a knowledge of experimental methods, or to take part in physical researches.

\section{NOTES}

A ReuTER'S telegram from Aden, of March 23, states that the steamer Calcutta arrived there from Zanzibar on the previous day with the body of the late Dr. Livingstone. We fear this must be regarded as final, and as shutting out any further hope ; we can only now do all possible honour to those remains which the doctor's faithful servants have so religiously preserved, A letter recently received from Zanzibar, by Mr. R. A. Laing, states that the body, after having been exposed to the sun for a month to diry, and then packed in a hollowed tree, was wrapped round with cloth, and the natives carrying it supposed it a bale of cloth, or kaniki.

H.M.S. Challenger arrived at Melbourne on the 17 th inst. : all well. On her voyage from the Cape of Good Hope, she reached the Antarctic Circle between E. long. $70^{\circ}$ and $80^{\circ}$.

IN connection with our leading article this week we see with pleasure that Mr. Mundella gave notice in the House of Com. mons on Monday, that " at an early day he would call attention to the Report of the Science Commissioners on National Museums, and move that, in the opinion of the House, steps should be taken to render National Museums and Galleries of Art more available for instruction for the purposes of Science and Art." We sincerely hope Mr. Mundella's motion will lead to some decided step in advance.

WE are sorry to have to announce the death of Johann Heinrich Maedler, the distinguished German astronomer, at Hanover, on March I4, at the advanced age of eighty. One of his best=known works is a Map of the Moon, of which he was the joint author with $M$. Beer. He was appointed Professor of Astronomy and Director of the Observatory at Dorpat in Russia alout 1840 , and was also the writer of various astronomical treatises :-- "Popular Astronomy," Berlin, I849; "The Existence of a Central Sun," Dorpat, 1846; "Lectures on Astronomy," Mittau, 1845-47, \&c.

WE are informed that the Royal Belgian Academy has re. solved to place the bust of Quetelet in the hall where its meetings are held. We believe no successor to the Directorship of the Brussels Olservatory has yet been named.

A $T$ the last meeting of the Royal Irish Academy, the Rev. Prof. Jellett resigned the office of president, and Wm. Stokes, M.D., D.C.L., F.R.S., was elected in his stead. Dr. Sullivan also resigned the secretaryship of the Academy on being made president of the Queen's College, in Cork, and Dr. E. Perceval Wright, F.L.S., was elected to the post. Dr. R. McDonnell, F.R.S., was also elected to the secretaryship of Foreign Correspondence in the place of Sir W. Wilde.

The Professorship of Astronomy in the University of Dublin, the holder of which is also Astronomer Royal of Ireland, is now vacant by the resignation of Dr. Francis Brinnow. Since its fundation this professorship has been held by Dr. Henry Ussher ( 1783 ), Dr. John Brinkley (I 790), Sir William Hamilton (1827), and Dr. Briinnow (1865). The election will be held on April 18. Rumour in Trinity College points to Prof. R. Ball, LL.D., F.R.S., as the most likely successor to Brinnow, a distinguished graduate of the University of Dublin in both pure mathematics and experimental physics. Dr. Ball acquired an extensive knowledge of astronomy duxing the several years that he acted as the late Lord Rosse's assistant at the Observatory at Parsonstown.

AT a numerously attended meeting of the Fellows of the Royal College of Surgeons, Ireland, held in the College Hall, Dublin, on

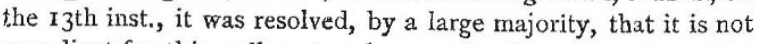
expedient for this college to take part in the proposed conjoint scheme for the examination of medical graduates in Ireland. The conjoint scheme had already been approved of by the Council of the College, by the Medical Professors and Board of Trinity College, Dublin, by the King and Queen's College of Physicians, Ireland, and by the Governors of the Apothecaries Hall.

The circular of the Board of Trade, respecting Storm Warnings, which appeared in our last, appears to require a few additional remarks by way of explanation. The circular 